Revista Médica Sinergia

Vol.3 Num:9

Setiembre 2018 pp: 9 - 13

ISSN:2215-4523

e-ISSN:2215-5279

http://revistamedicasinergia.com

\section{LINFOMA ASOCIADO A MUCOSAS}

(Mucosa-associated lymphoid tissue lymphoma)

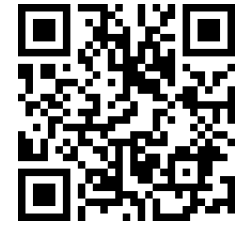

${ }^{1}$ Médico general, graduada de la Universidad Latina de Costa Rica (U.Latina), médico en Clínica aguas claras, Limón, Costa Rica. Código médico: 12557 draarroyoh@gmail.com

\author{
${ }^{1}$ Dra. Karla Arroyo Herrera \\ Clínica Aguas Claras, Limón, Costa Rica \\ draarroyoh@gmail.com \\ https://orcid.org/0000-0001-8897-9636
}

\section{RESUMEN}

Linfoma de tejido linfoide asociado a mucosa (MALT) se desarrolla en el tejido linfoide, en la mucosa o tejido que recubre los órganos del cuerpo, en las cavidades corporales que incluyen: el tracto gastrointestinal, los pulmones; ojos; piel; glándulas salivales; glándula tiroides; y pechos.

El linfoma MALT representa aproximadamente el 6\%-8\% de los casos de linfoma no Hodgkin (NHL), por lo que es el tercer tipo más común de NHL. Estos linfomas son generalmente de crecimiento lento.

Los estudios de pacientes con linfoma MALT de bajo grado han confirmado una alta incidencia de infección por Helicobacter Pylori y sugieren que la infección es anterior a la transformación neoplásica.

En Costa Rica siempre debemos tener en cuenta este diagnóstico porque existe una alta prevalencia de la infección por helycobacter pylori en la población.

PALABRAS CLAVES: linfoma, Helicobacter Pylori, tejido, infección, neoplasia, celulas B, inmunidad, nmunohistoquímicas, criterio de Wotherspoon.

\section{ABSTRACT}

Mucosa-associated lymphoid tissue (MALT), MALT lymphoma develops in the lymphoid tissue, in the mucosa or tissue that lines body organs, or in body cavities including: the gastrointestinal tract, lungs; eyes; skin; salivary glands; thyroid gland; and breasts.

MALT lymphoma accounts for approximately $6 \%-8 \%$ of non-Hodgkin lymphoma (NHL) cases, making it the third most common type of $\mathrm{NHL}$. These lymphomas are usually slow-growing.

Studies of patients with low-grade MALT lymphoma have confirmed a high incidence of Helicobacter Pylori infection and suggest that the infection predates neoplastic transformation.

In costa rica you should always think about this diagnosis because we 
have a high prevalence of the Helicobacter Pylori infection.

KEY WORDS: lymphoma, helicobacter pylori, tissue, infection, neoplasia, B cells, immunity, immunohistochemistry, Wotherspoon criteria.

\section{INTRODUCCIÓN}

El linfoma estranodal asociado a mucosas (MATL) es el tercer linfoma no Hodgkin en frecuencia un total del $6 \%$ al $8 \%$, el mismo es indolente, crónico por lo general, y con una largo periodo de sobrevivencia, sin embargo, contrario a los linfomas agresivos el MALT termina siendo incurable. Para lograr el diagnóstico del MALT se requiere pericia patológica ya que debe de ser un diagnóstico morfológico, molecular e inmunohistoquímico.

En nuestro país y debido a la alta prevalencia de Helicobacter Pylori en la población, se debe de pensar en este diagnóstico al encontrar síntomas $\mathrm{T}$, al realizar la gastroscopia y la biopsia de las lesiones, pues son fácilmente confundidas a la vista con cáncer gástrico, inclusive por gastroenterólogos de amplia experiencia; La erradicación del mismo se logra con la toma de antibiótico terapia contra Helicobacter Pylori y es necesario realizar controles para valorar la mejoría y desaparición de las lesiones.

Se han asociado diversas infecciones a la aparición de MALT sin embargo, la más firmemente asociada es el Helicobacter Pylori, la misma posee capacidad linfogénica y crea un microambiente que permite la reproducción de las células $B$ neoplásicas; al erradicar el Helicobacter Pylori se erradican las lesiones en un 75
$\%$ de los casos. Otras de las bacterias asociadas son Chlamydia psattici, hepatitis $\mathrm{C}$, en MALT de glándulas salivales y Campylobacter jejuni.

\section{DIAGNÓSTICO PATOLOÓGICO}

\section{CARACTERÍSTICAS MORFOPATOLÓGICAS}

Todo linfoma debe ser diagnosticado de una muestra excisional de ganglio linfático, en el caso del MALT no es la excepción, un hallazgo de células neoplásicas en el área marginal del ganglio, con un comportamiento de expansión interfolicular en capas, es el hallazgo común en la muestra, además las células de linfoma presentan con características citoplasmáticas específicas, como eosinofilia que dejan un espectro en racimos, producto de las células degeneradas, por lo que un patólogo - hematólogo experimentado debe de analizar la pieza y mediante técnicas microscópicas e inmunohistoquímicas dar el diagnostico fiable para inicial el abordaje del paciente.

\section{CARACTERÍSTICAS HISTOLÓGICAS DEL MALT Y SITIOS DONDE SE PRESENTA}

- MALT - GÁstrico

La mayoría se detecta en paciente en los cuales la gastroscopia muestra 
TABLA 1.1. Criterios histológicos establecidos por Wotherspoon.

\begin{tabular}{|c|c|l|}
\hline $\mathbf{0}$ & Normal & $\begin{array}{l}\text { Ocasionales células plasmociticas en la lámina propia, sin } \\
\text { folículos linfoides. }\end{array}$ \\
\hline $\mathbf{1}$ & Gastritis crónica activa & $\begin{array}{l}\text { Lamina propia infiltrada por linfocitos pequeños en } \\
\text { agrupaciones pequeñas, sin folículos linfoides, No hay lesión } \\
\text { linfoepitelial. }\end{array}$ \\
\hline $\mathbf{2}$ & $\begin{array}{c}\text { Gastritis crónica activa } \\
\text { con formación de folículos } \\
\text { linfoides }\end{array}$ & $\begin{array}{l}\text { Presencia de prominentes folículos linfoides rodeados por } \\
\text { células del manto y plasmocitos, no hay lesión linfoepitelial. }\end{array}$ \\
\hline $\mathbf{3}$ & $\begin{array}{c}\text { Infiltrado linfoide } \\
\text { sospechoso } \\
\text { probablemente de } \\
\text { naturaleza reactiva }\end{array}$ & $\begin{array}{l}\text { Folículos linfoides rodeados por linfocitos pequeños que } \\
\text { infiltran difusamente la lámina propia y ocasionalmente son } \\
\text { intraepiteliales. Requiere análisis de inmunofenotipo y/o } \\
\text { molecular para confirmar o excluir. }\end{array}$ \\
\hline $\mathbf{4}$ & $\begin{array}{c}\text { Infiltrado linfoide } \\
\text { sospechoso } \\
\text { probablemente linfoma }\end{array}$ & $\begin{array}{l}\text { Folículos linfoides rodeados por células de la zona marginal } \\
\text { que infiltran difusamente la lámina propia e intraepiteliales en } \\
\text { grupos pequeños. Requiere análisis de inmunofenotipo y/o } \\
\text { molecular para confirmar o excluir. }\end{array}$ \\
\hline $\mathbf{5}$ & $\begin{array}{c}\text { linfoma MALT } \\
\text { matencia de denso y difuso infiltrado inflamatorio con }\end{array}$ \\
\hline
\end{tabular}

inflamación no especifica, ulceras , erupciones ya presentadas en anteriores ocasiones, y el mayor problema es el diferenciarlo de gastritis asociada a $\mathrm{H}$ pylori por este motivo se crea la escala de Wotherspoon. Ver TABLA1.1.

\section{- MALT - PULMONAR}

Se presenta como nódulo único, múltiple o consolidaciones en un paciente sin síntomas o con tos y disnea. Este tipo de linfoma presenta una infiltración linfangitica que se extiende en el área bronco vascular, septo interlobular o pleura visceral, que confluyen en masas y afecta el parénquima pulmonar. Las células $B$ y el patrón específico lo distinguen de una bronquitis folicular, neumonía linfoide intersticial y de una hiperplasia linfoidea. También se pueden observar fibrosis, infiltración no necrotizante transmural de grandes vasos, granulomas no caseoaos.

\section{- MALT - GLÁNDULAS SALIVALES}

La mayoría del MALT en estas zonas son precedidos por lesiones benignas linfoepiteliales $0 \quad$ sialiadenitis. Caracterizado por tejido acinar atrófico con infiltraciones de linfocitos pequeños, células plasmáticas en forma de islotes que infiltran mioepitelio, y ductos con células $B$ monolíticas pálidas, que tienden a cavitar y producir reemplazo linfoepitelial en los folículos y dilatación en los ductos generando una apariencia cística.

Existe evidencia de MALT en anexos oculares, piel y glándula tiroides, por lo que se debe de tener en mente, así como recordar la recomendación de la OMS de realizar la clasificación de 
linfoma difuso de células $B$ si existen racimos de blastos grandes en un número mayor a 20, o la combinación de celular b grandes y pequeñas para así realizar el tratamiento correspondiente, esto debido al comportamiento agresivo del mismo, contrario al crónico del MALT.

\section{- Patología molecular PaRA EL DIAGNOSTICO}

En ciertos casos que se sospecha MALT no son suficientes la inmunohistoquimica y la morfología por lo que se deben de aplicar técnicas moleculares que reflejen clones de células $B$, a través de análisis de PCR 0 la identificación de anormalidades cromosómicas (translocaciones). Ver CUADRO 1.1.

CUADRO 1.2. Translocaciones más prevalentes en el MALT.

- $\mathrm{t}(11 ; 18)(\mathrm{q} 21 ; \mathrm{q} 21) / \mathrm{API} 2-\mathrm{MALT1}$

- $\mathrm{t}(14 ; 18)(\mathrm{q} 32 ; \mathrm{q} 21) / / \mathrm{IGH}-M A L T 1$

- $\mathrm{t}(1 ; 14)(\mathrm{p} 22 ; \mathrm{q} 32) / \mathrm{IGH}-\mathrm{BCL} 1$

\section{PRONOSTICO}

El pronóstico es menos favorable si hay presencia de linfoma difuso de células $B$, también incide la respuesta al tratamiento antibiótico terapia, por lo que se creé que el linfoma difuso de células
$\mathrm{B}$, es resistente al antibiótico, además, la presencia de varias mutaciones como Bcl10 o NFKB que se sabe empeoran la respuesta al mismo, básicamente esto muestra que mientras más tiempo se tarde en erradicar el causante peor será el pronóstico del paciente.

\section{SEGUIMIENTO POST TRATAMIENTO}

La sobrevivencia de los pacientes con MALT sucede en el 85 al $95 \%$ de los casos, sin embargo un 25 al $35 \%$ de los pacientes hacen recaída, sobre todos los de MALT no gástrico, por lo que se deben de seguir con biopsias en busca de células $B$ y adenocarcinomas, con una frecuencia de cada 3 a 6 meses los primeros 2 años y anualmente luego, para lograr un óptimo control de la enfermedad.

\section{- ADENOCARCINOMA POST MALT}

Se debe siempre descartar un adenocarcinoma, por ambos compartir la etiología de Helicobacter pylori, además por haberse descrito casos de cáncer gástrico temprano post remisión completa del Malt.

\section{BIBLIOGRAFÍA}

1. The Non-Hodgkin's Lymphoma Classification Project A clinical evaluation of the International Lymphoma Study Group classification of non-Hodgkin's lymphoma. Blood 1997893909-3918. [PubMed].

2 Isaacson P G, Du M Q. MALT lymphoma: from morphology to molecules. Nat Rev Cancer 20044644-653 [PubMed]. 
3. Wotherspoon A C, Ortiz-Hidalgo C, Falzon M R. et al Helicobacter pylori-associated gastritis and primary B-cell gastric lymphoma. Lancet 19913381175-1176. [PubMed].

4. Parsonnet J, Hansen S, Rodriguez L. et al Helicobacter pylori infection and gastric lymphoma. N Engl J Med 19943301267-1271. [PubMed].

5. Hussell T, Isaacson P G, Crabtree J E. et al The response of cells from low-grade B-cell gastric lymphomas of mucosa-associated lymphoid tissue to Helicobacter pylori. Lancet 1993342571574. [PubMed].

6. Hussell T, Isaacson P G, Spencer J. Proliferation and differentiation of tumour cells from B-cell lymphoma of mucosa-associated lymphoid tissue in vitro. J Pathol 1993169221-227. [PubMed].

7. Ferreri A J, Guidoboni M, Ponzoni M. et al Evidence for an association between Chlamydia psittaci and ocular adnexal lymphomas. J Natl Cancer Inst 200496586-594. [PubMed].

Recepción: 15 Junio de 2018

Aprobación: 10 Agosto de 2018 